\title{
Quantification of the sources of soluble organic N (SON) from new litter or indigenous soil in a typical subtropical forest
}

\author{
Xian Ding ${ }^{1}$, Yue Chang ${ }^{1}$, Hongbo Hou ${ }^{1}$, Peiqin Peng ${ }^{1}$, and Wenhua Xiang ${ }^{1}$ \\ ${ }^{1}$ Central South University of Forestry and Technology
}

December 14, 2020

\begin{abstract}
Decomposition of forest litter plays a major role in nitrogen $(\mathrm{N})$ dynamics in soil. But to which extent that forest litter affects soil $\mathrm{N}$ and how much soil $\mathrm{N}$ is derived from the new litter remains unknown. An in-situ soil column experiment with 14-month litter decomposition was conducted to examine the effect of litter retention on soil $\mathrm{N}$ dynamics in a typical forest of subtropical China in 2018. Litter removal in the soil column was used as a control treatment, while natural litter or identical amount of $15 \mathrm{~N}$ labeled litter was added to soil columns as litter retention treatment. The results showed that litter removal caused a continuous decrease in concentration of soil soluble organic nitrogen (SON) in the first 5 months, and then SON began to accumulate and its concentration went up in spring showing obvious seasonal change. Litter retention accelerated the reduction of soil SON concentration in the first 2 months, while maintained a high concentration after that period. Soil NH4+-N derived from litter was nitrified rapidly, and newly formed NO3-N was quickly immobilized or lost. Only $1.8 \%$ of soil SON came from litter $\mathrm{N}$ and $98.2 \%$ from indigenous soil $\mathrm{N}$ under the decomposition of labeled litter. Litter provided supplementation $\mathrm{N}$ to form new soil SON continuously, however, only a small part of SON was relatively stable, and SON played the role of reserve and regulatory pool. Soil SON and TN were formed after long-term litter accumulation and decomposition.
\end{abstract}

\section{Hosted file}

Ding 2020-12-10-LDD-1.pdf available at https://authorea.com/users/382802/articles/498673quantification-of-the-sources-of-soluble-organic-n-son-from-new-litter-or-indigenoussoil-in-a-typical-subtropical-forest

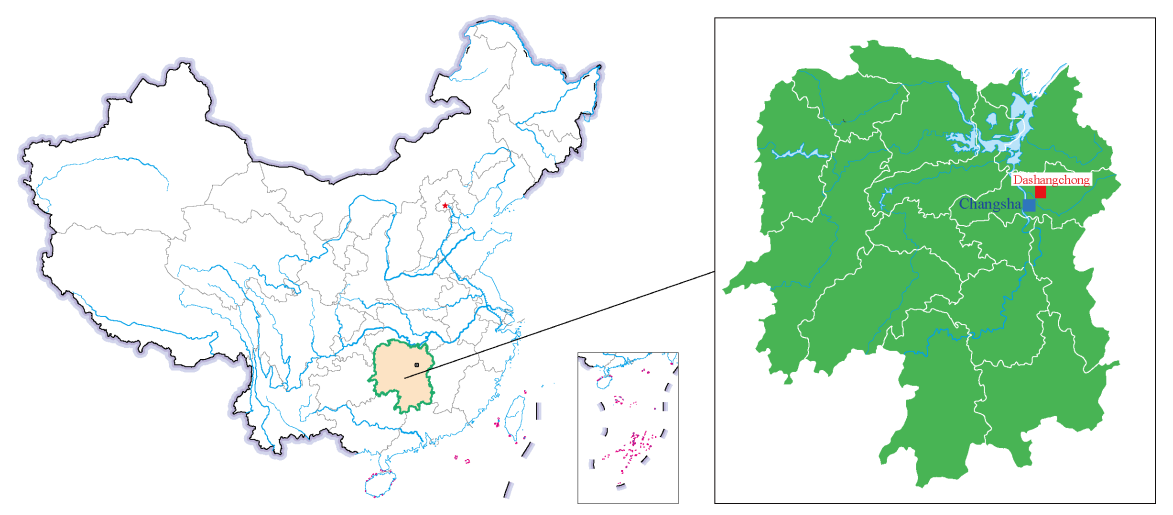



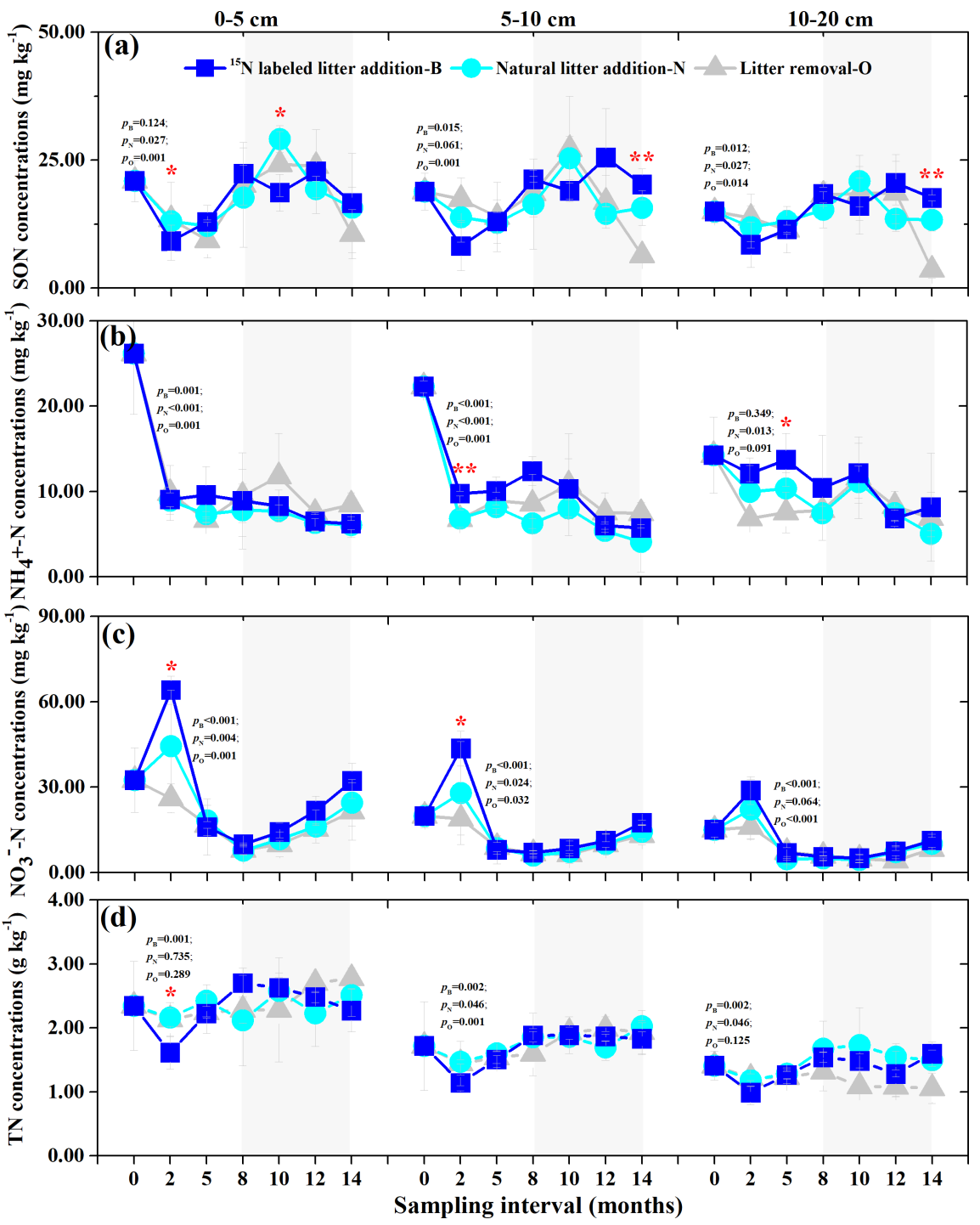

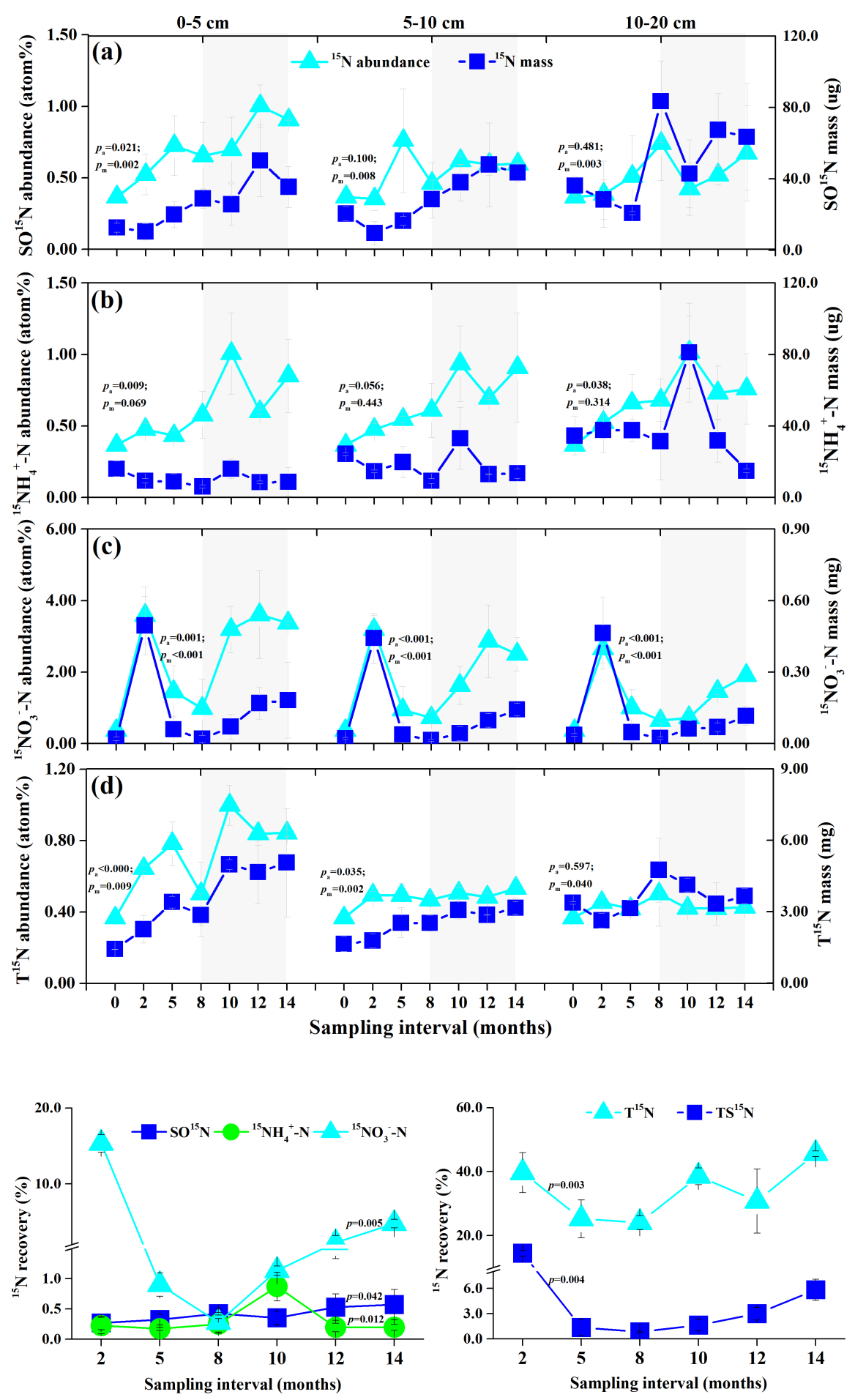

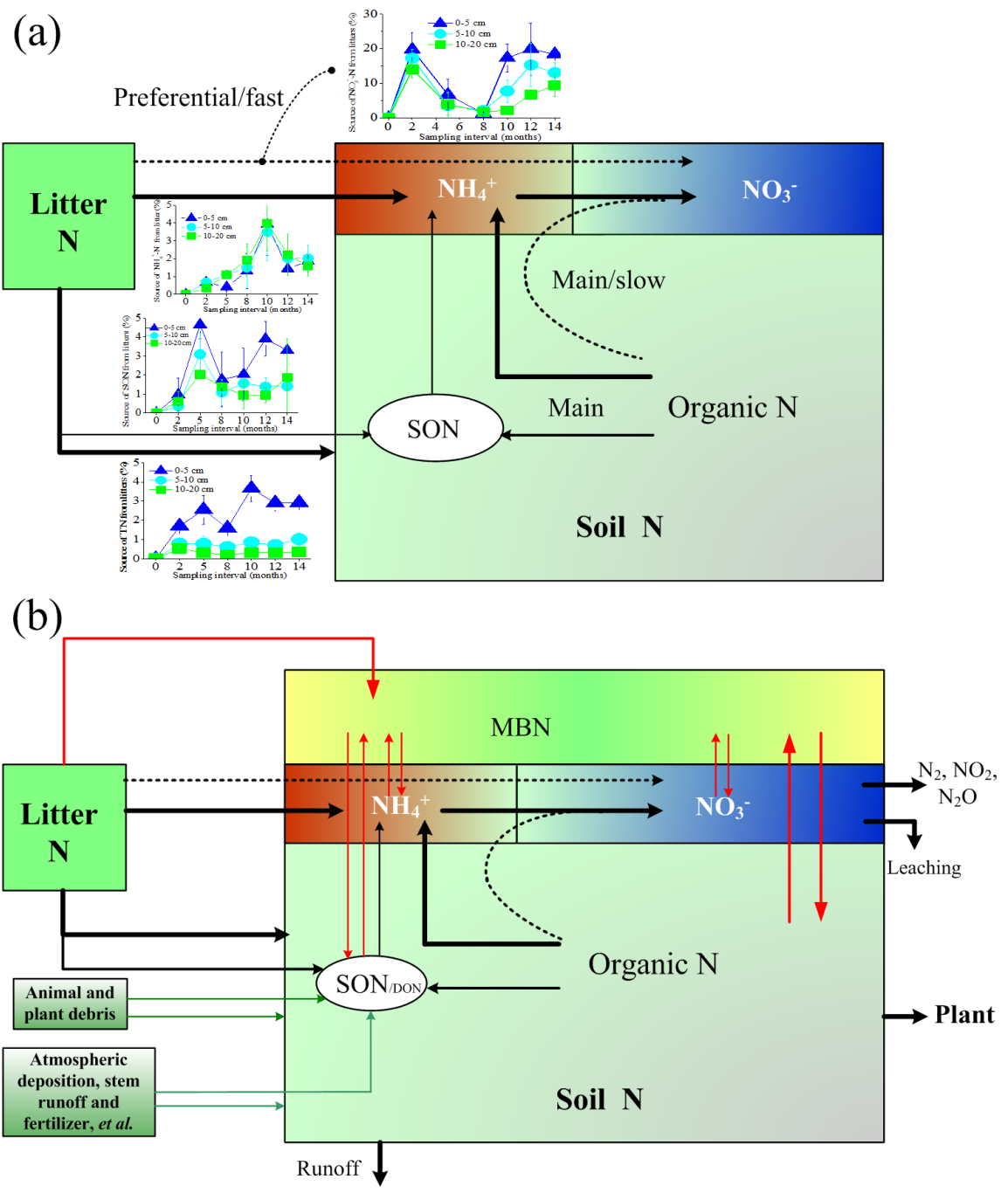